\title{
The Effect of In-Service Training Courses on the Teacher's Attitude and Performance
}

\author{
Nayereh Shahmohammadi \\ Research and Educational Planning Organization, \\ Ministry of Education, Iran
}

\section{Doi:10.5901/jesr.2013.v3n9p79}

\begin{abstract}
The present article reports on a research designed to examine the effect of teachers in-service training programmes on their attitude and performance. The study was conducted on 100 teacher's trainees in $6^{\text {th }}$ Education district of Tehran. An attitude questionnaire was used once at the beginning and once at the end of the training course to check the participants' attitude change. The teacher's performance was then observed using an observation checklist. A stimulated recall interview was conducted to check the reasons for the discrepancies between the programme guidelines and the teacher's performance. The results of the attitude questionnaire showed that the teacher's attitude had changed significantly in one area of the three areas under investigation. The analysis of the data collected through the observation checklist and the stimulated recall interview showed that the teacher's trainees performance was not acceptable in the area their attitude had undergone a change. The article concludes by suggesting that attitude change does not necessarily lead to a change in teachers performance.
\end{abstract}

Keywords: teacher inservice training programmes, teacher education, teacher improvement, teacher qualifications, teacher skills, Pre-service teacher education

\section{Introduction}

Almost 20 years ago, Sarason, Davidson, and Blatt (1986) called teacher preparation an "unstudied problem" and urged researchers to look at what actually went on inside programs as a basis for understanding their effects on teachers. Just as teachers can make a difference in children's learning, so teacher educators presumably have an impact on their "student teachers." Teachers may benefit from teacher education in many qualitatively different ways: They may acquire knowledge, alter their beliefs, gain skills, or develop new attitudes and dispositions. And all of these outcomes may be important to teaching practice.Rather than looking to see whether candidates have acquired the particular knowledge or skills transmitted by a program, nowadays researchers in this field are mostly interested in how the views and performance of teachers change as they participate in different kinds of teacher education programs. In most inservice's training institutes before while teaching in the school, a teacher is required to undergo short term in-service training courses. The content of these courses in most places is oriented toward the knowledge and understanding, skills and dispositions, attitudes and beliefs that teacher educators seek to alter in teachers. But the question is: Do these training courses actually have any effect on the teachers' attitude and performance? This study was aimed at investigating those dimensions of programs that are most likely to contribute to changes in teachers' attitudes and performance. Through a case study a group of teachers undergoing a short term teacher training course were followed over time to trackchanges in their attitude and practice. 


\section{Background}

During the early 20th century, there was this belief that teaching was an art and that teachers were born rather than made. Aron (1922) argued that "As long as the teacher depends on a pedagogical bag of tricks and not on skills in teaching based on a thorough knowledge of and about the material he is teaching, namely language, just so long language teaching cannot claim classification as a profession" (p.77). In this regard, in 1915 in New York some attempts started for a formal, statewide assessment of teacher qualifications for certification purposes. So by 1926, in the state of New York, a bachelor's degree, specified courses in education, and the languagespecific exam became necessary requirements for gaining certification. By 1941, teacher development was anestablished field, even though its need was not yet fully accepted by traditional academics. During the early to mid-1960s the

Educational Resources Information Center (ERIC) was funded by the U.S Office of Education to "concentrate on research and programs dealing with pre-service and inservicepreparation of teachers" ("Notes and News," MLJ , 52, 1968, p.440) but even with these efforts made in upgrading teacher effectiveness during the 1960s and the prediction that "a new phase" in the history of FL teaching would begin (p.18), few of the "innovations" had a lasting impact.

In 1980 Goepper and Knorre saw a strong need for intensive pre-service and in-service preparation. Although the contents and experiences offered in their model of teacher training did not differ a lot from those described by others they believed teacher training was no longer exclusively a training course to familiarize student teachers with instructional materials to provide a "bag of instructional drills and tricks" for a classroom. For the first time, their model included issues such as, "appropriateness of particular methodologies for students of varying aptitudes, ages, and skills" (p. 447).

Nowadays teaching is no longer seen exclusively as an art, as it was during the early parts of the century. Although the "creative element" will always play an important role in good teaching, the current thought is that there are principles,processes, skills, behaviors, techniques,strategies, beliefs, and attitudes that have an impact on teaching and learning and that they can be studied and taught. Research could help both teacher educators and teacher education policymakers to understand better whether and how teacher education makes a difference. Many researchers have concentrated on the teacher component of teacher education (Goodman, 1986; Hodges, 1982; Silvernail and Costello, 1983; Tabachnik and Zeichner, 1984).

The typical research design for studies of teachers has been a single-group longitudinal design to compare before and after data on teachers' beliefs or knowledge or skills. Many researchers have studied in-service programs rather than pre-service programs (Carpenter, Fennema, Peterson, Chang, and Loef, 1989; Coladarci and Gage, 1984; Griffin and Barnes, 1986).

In-service programs often have more clearly defined goals: many of them are preparing teachers in very specific subjects, for instance, on teaching secondary science, or on teaching elementary reading. So researchers have a more manageable task when they study in-service teacher education. Still other researchers have limited their inquiry to description of parts of the system rather than exploring relationships among parts.(e.g. American Association of Colleges of Teacher Education, 1987, 1989; Howey and Zimpher, 1989, 1990). Instead of looking at how teacher inservce programs influence teachers, these researchers have looked at what teacher inservice programs are like.All of these approaches to research in teacher inservice education have been profitable.

One way to think about the role of teacher inservice education is to assume that teachers themselves might be the best source of evidence. Teacher educators often try to find out whether a teacher inservice training program made a difference by surveying the teachers and asking them if the program made a difference.Adams and Craig (1983) surveyed teacher inservice trainig programs in 1980 and found that 74 percent claimed to be conducting some sort of completion of their background knowledge. One such survey was conducted by the National Education 
Association (NEA).NEA surveyed its members and asked them to evaluate the contribution of 14 different sources of knowledge about teaching, one of which was in-service teacher education (Smylie, 1989). The in-service teacher education program was ranked by these teachers 13 th out of the 14 sources of knowledge. The highest-rated source of knowledge was direct experience.

In 1975, Pigge (1978) performed a survey which provided the same results. He surveyed graduates of Bowling Green University who participated in a special training programes and gave them a list of 26 competencies on which the respondents were to rate themselves. Teachers felt they were at least adequate on 14 out of the 26 proficiencies. Pigge also asked teachers how important these various competencies were to their work and where they learned these competencies. Generally speaking, teachers thought that those competencies most necessary to their work were learned on the job, whereas those considered least necessary were acquired in their teacher inservice training programs.

Some have argued that teacher judgment as an outcome is not reliable and so this can be a limitation in these studies, for several reasons: First, we do not know what criteria teachers use when they make these assessments. For example when a teacher rates her/himself as adequate or better than adequate, on what basis does she make this judgment? Are teachers' criteria the same as an observer's criteria? Similarly, when a teacher claims a program has contributed to her knowledge or skills, or has not contributed to her knowledge or skills, do we know for sure how accurate these judgments are?

Strang, Badt, and Kauffman (1987) provide some evidence which support the abovementioned argument. In their study, they measured teachers' skills both before and after a program treatment. They also asked, afterwards, the teachers themselves to estimate the degree to which they had changed. The researchers' assessment of teacher change showed their proficiency moving from 52 percent to 87 percent.

However, the teachers' assessments of their change showed a movement from 81 percent to 85 percent. Therefore, as we can see, one cannot rely on the outcome measures based on teachers' self-evaluation.So another way to study whether or how teacher training programmes makes a difference is to follow teachers through their training programmes, gathering data on them at several points along the way, to see whether and how their ideas about teaching change over time. Researchers working within this genre want to learn what teachers are like when they enter their programs, how they change over time in response to their programs, and what they are like when they finish.

\section{Method}

The present study can be categorized as descriptive with a case study design. The fieldwork was conducted in a teacher training Institute in $6^{\text {th }}$ education district in Tehran with the aim to study teachers participating in a shortterm Teacher Training Course (TTC). The participants were a sample of 100 female teachers in this way the gender was controlled. The study limited to teachers majored in fields other than English such as French and Economics.The instruments used in this study were a questionnaire, an observation checklist and a stimulated recall interview.

\section{Questionnaire}

To get an idea of the training course content and activities, one of the researchers attended a whole training course and made a record of the content and activities in that program. Based on the record of content and activities, a 35-item 5-point-scale questionnaire was designed.The purpose of the questionnaire was to examine the changes in the participants'attitude. Twenty six out of the thirty five items of the questionnaire were adopted from Christison \& Bassano's (1984) Teacher Self-Observation Form, cited in Brown (2001. p 435) and the rest ( 9 items) were added by the researchers. To check the content validity of the questionnaire,another questionnaire with the 
same items but a different scale (3-point-scale:relevant, no idea, irrelevant) was designed and given to the trainers of the training course in order to elicit their views on its content. They all confirmed the items to be consistent with the syllabus taught in the training course classes. The questionnaire was then piloted with a group of 27 teachers similar to the target participants and its reliability which was calculated through Guttman split-half formula turned out to be 0.90 .

\section{Observation Checklist}

In order to observe the teachers' teaching performance, an observation checklist was prepared. The items listed in the researcher's checklist were compared with a checklist in Brown (2001. p 432). The items in this checklist which is called "Teacher Observation Form: Observing other Teachers" overlapped with those included in the researcher's checklist. By comparison, 26 items which covered the syllabus and content of the TTC were selected. Therefore a 26-item 5-point Likert-scale observation checklist was designed. The five categories were: $4=$ excellent, $3=$ above average, $2=$ average, $1=$ unsatisfactory, $N / A=$ not applicable. Stimulated Recall Interview The observed lessons were audiorecorded.The aim was to have evidence of what the teachers had said and done in class. The results of the observation checklist were used to prepare a list of the strong and weak points of each teacher.The weak points of the teachers' profiles were complemented with episodes of teaching which were not consistent with what had been taught in the teacher training classes.

These episodes were used in the stimulated recall interviews as evidence for the weak points. Procedure The data for this study were collected in 3 phases over a period of 5 weeks. In phase one, one of the researchers participated in the Teacher Training Courses of an institute which was a 3 week course, 3 hours a day except for Thursdays and Fridays. The purpose was to document the course content and activities. Based on the content of the course an attitude questionnaire was designed which was administered to the participants once at the beginning of the course (before any training was given) and once at the end of the course (after the last session of training).

The teacher observations were done in phase two, week 4. For this phase of the research an observation checklist was used. The researcher attended each of the100 teachers' classes (two classes a day). The teachers were informed that an observer would participate in their classes and that the observations were intended to be used for research purposes only.In phase three, the stimulated recall interviews were conducted. After preparing the profiles, contacts were made with the teachers and an interview was scheduled with them. The interview started with the strong points of the teachers' profiles and then shifted to the weak points observed during classroom observations. The teachers were asked for the reasons and the rationale behind the digressions and records were made of the answers in their profiles. Each interview lasted 15-30 minutes.

\section{Results}

To answer the first question of the study which dealt with attitude change,the uestionnaire data were analyzed.The questions in this questionnaire were categorized under 3 sections: Learning Environment, Individuals, and Activity. A paired sample t-test was used to compare the means of the same group at two different stages of the short term training course.

Table 1. The Paired t-test obtained for the "Learning Environment" section

\begin{tabular}{|c|c|c|c|c|c|}
\hline & $\mathrm{M}$ & $\mathrm{SD}$ & $\mathrm{t}$ & $\mathrm{df}$ & $\mathrm{Sig}$ \\
\hline Pair 1 - STAGE2 & -2.43 & 1.71 & -5.69 & 98 & .00 \\
\hline
\end{tabular}

The result of the paired t-test for the first section of the questionnaire (the learning environment) 
in table 1 shows that the difference was significant $(P<0.05)$ and so according to this result the group underwent a significant change in attitude.

Table 2. Paired t-test obtained for the "Individuals" section

\begin{tabular}{|c|c|c|c|c|c|}
\hline & $\mathrm{M}$ & $\mathrm{SD}$ & $\mathrm{t}$ & $\mathrm{df}$ & $\mathrm{Sig}$ \\
\hline Pair 1 - STAGE2 & -2.00 & 2.23 & -2.68 & 99 & .028 \\
\hline
\end{tabular}

Table 2 presents the results of the paired t-test run on the questions related to the "individuals". As the figure $(0.28)$ indicates, the difference was not significant $(P>0.05)$.

Table 3. Paired t-test obtained for the "Activity" section

\begin{tabular}{|c|c|c|c|c|c|}
\hline & $\mathrm{M}$ & $\mathrm{SD}$ & $\mathrm{t}$ & $\mathrm{df}$ & $\mathrm{Sig}$ \\
\hline Pair 1 - STAGE2 & -.30 & 6.51 & -.14 & 100 & .80 \\
\hline
\end{tabular}

Table 3 shows that the possibility level for the last section (the activity) is 0.80 which is bigger than alpha level of $0.05(0.88>0.05)$ and so in this section the difference between the two means is not significant. In the second phase of the research an observation checklist based on the content of the training course was designed and used by the researchers. The aim of this phase was to observe the teaching practice of the teachers to answer the second research question which dealt with effect of the short term in-service teacher training course on the teachers' performance. To answer this question, one of the researchers attended each of the teachers' classes and observed their teaching practice. Based on the outcome of the checklists, profiles were designed for each of the teachers. The observation checklist was designed in four main sections: Presentation, Execution/ Method, Personal Characteristics, Student/Teacher Interaction.

Table 4 below provides the frequency of the teachers' weak points regarding the above sections.

Table 4. Frequency table for the teachers'weaknesses in the main categories of their teaching practice.

\begin{tabular}{|l|c|}
\hline Presentation & 13 \\
\hline Execution/ Method & 14 \\
\hline Personal Characteristics & 0 \\
\hline Teacher/ Student Interaction & 97 \\
\hline
\end{tabular}

As can be seen in the above table the teachers did not have any weak point in regard to "personal characteristics". The weak points in the teachers' performance were observed mostly in the other three areas

\section{Discussion}

The above mentioned results for the first stage of the research indicate that the training course significantly affected the teachers' attitude in only the "learning environment"category which consists of items listed under three subcategories: A) Relationship with Students, B) Presentation and C) Culture and Adjustment. The reason for the lack of change in the other two sections (Individuals and Activity) might be due to the fact that the teachers' attitude toward these two sections had already been positive as their responses to the items were mostly in the positive range both before and after the training course. As mentioned before, the topics and subjects taught in the training course were chosen from the basics of teaching and learning. The most essential matters and issues that all experienced teachers had practiced in their teaching before and the inexperienced teachers had observed,during their school years, in their own practice of 
teaching. So they already had a positive attitude towards them (maybe unaware of it themselves). This could justify the pattern of change in the trainees' attitude.As for the results of the second phase of the research, according to senior (2006) it is nearly impossible for teacher to implement all the principles of teaching that they have been taught in training courses since these courses are overloading teachers with a plethora of methods, and teaching skills. This may account for the high number of mistakes in the two areas of presentation and execution/method.

Also by comparing the results obtained from the questionnaires and the observation checklists, we noticed that insome cases there was a mismatch between the student teachers' attitude in stage two and their teaching practice in class. That is to say they failed to put into practice what they valued through the attitude questionnaire. The researchers are of the opinion that the reason why the teachers did not follow some of the training guidelines might be due to their being overwhelmed with a plethora of principles on the one hand and being new to the atmosphere and inexperienced on the other. This might have made it difficult for them to make on the spot decisions in spite of their willingness to do so. This finding supports Ajzen's (1988) claim that teachers' attitudes may be something and their actual behaviors may be something else based on the opportunities and resources available to them. This point is consistent with the common observation that some teachers who agree with particular types of activities do not carry them out in their classrooms. For these teachers, attitude is not predictive of their behavior. The point to remember is that teachers' inadequate performance should not be considered as an indication of their incompetence. If they are given enough time and practice they would probably gain the confidence to be more judicious in their decision making.

So, only one observation immediately after the training course may not suffice.Observing the teachers over time may provide more dependable results. But there were also some cases in which the teachers who had experience in teaching also did not follow the training course guidelines.The reason might be the incompatibility of what the teachers had gained through years of experience and what was introduced as sound practice in the training course. Their experience might have convinced them that what the training course introduced as effective practice was not feasible. This case is also in line with what Hollingsworth (1992) has theorized. He claims that prior knowledge and experience serve as a filter to pedagogical learning during the pre-service years, altering how pedagogical instruction is learned and enacted by teachers. This was actually observed in this study since some teachers who had a few years of experience in teaching did not follow exactly what was prescribed to them in the training course and preserved their previous beliefs and personal theories. As individuals, teachers have particular temperaments and personality traits that influence how they approach new ideas and situations. Thus, learning outcomes in teacher education are a function of both what programs offer and what teacher trainees bring to the training course.

\section{Pedagogical Implications}

The results of the present study suggest that we should modify our expectations from short-term teacher training courses. Training is useful to the extent that trainee teachers are introduced to a range of teaching procedures consistent with the course design and the adopted approach.However, the extent to which these procedures would be used is limited by the way they are interpreted by the teachers in the light of their ingrained beliefs and their assessment of the resources and constraints of the teaching context which would determine the feasibility of the introduced procedures. The implication is that teachers should be convinced of the theoretical rationale of the procedures and their feasibility before they incorporate them in their arsenal of teaching procedures. This might require a period of experimentation with the introduced procedures which would in turn necessitate a follow-up process designed to provide support and supervision to the teachers in the experimentation phase. Short term teacher training courses are currently offered without a follow-up which limits their usefulness to a great extent. To enhance their usefulness the training course designers should arrange for a follow-up in which trainee 
teachers are observed and encouraged to experiment with the new procedures.

\section{References}

Adams, R. D., and Craig, J. R. (1983). 'A Status Report of Teacher Education Program Evaluation.' Journal of Teacher Education, 34, 33-36.

Ajzen, I. (1988): Attitudes, Personality, and Behavior. Milton Keynes: Open University Press.

Aron, A. W. (1922). The Linguistic Background of the Modern Language Teacher. MLJ, 7, 75-83.

Brown, H. D. (2001). Teaching by Principles; An Interactive Approach to Language Pedagogy. 2nd Ed. San Francisco:Pearson Education. Carpenter, T. P., Fennema, E., Peterson, P. L., Chang, C., and Loef,

M. (1989). Using Knowledge of Children's Mathematics Thinking in Classroom Teaching: An Experimental Study. American Educational Research Journal, 26, 499-531.

Coladarci, T., and Gage, N. L. (1984). Effects of a Minimal Intervention on Teacher Behavior and Student Achievement. American Educational Research Journal, 21, 539-555.

Goepper, J. B., \& Knorre, M. (1980). Pre- and In-service Training of Graduate Teaching Assistants. MLJ, $64,446-450$.

Goodman, J. (1986). What Students Learn From Early Field Experiences: A Case Study and Critical Analysis.J ournal of Teacher Education, 36, 42-48.

Griffin, G., and Barnes, S. (1986). Using Research Findings to Change School and Classroom Practices: Results of an Experimental Study. American Educational Resear Blame the Cooperating Teacher Who Can you Blame? Journal of Teacher Education, 33, 25-29.

Hollinsworth, S. (1989) 'Prior Beliefs and Cognitive Change in Learning to Teach,' American Educational Research Journal, 26, 160-89.

Howey, K. R., and Zimpher, N. L. (1989). Pre-service Teacher Educators' Role in Programs for Beginning Teachers. Elementary School Journal, 89, 451-471.

Pigge, F. L. (1978). Teacher Competencies: Need, Proficiency, and Where Proficiency Was Developed. Journal of Teacher Education, 29, 70-76.

Sarason, S. B., Davidson, K. S., and Blatt, B. (1986). The Preparation of Teachers: An Unstudied Problem in Education. Cambridge, MA: Brookline.

Silvernail, D. L., and Costello, M. H. (1983). The Impact of Student Teaching and Internship Programs on Pre-service Teachers' Pupil Control Perspectives, Anxiety Levels, and Teaching Concerns. Journal of Teacher Education, 36, 32- 36.

Smylie, M. A. (1989). Teachers Views of the Effectiveness of Sources of Learning to Teach, The Elementary School Journal, 89, 543-58.

Strang, H. R., Badt, K. S., and Kauffman, J. M. (1987). Microcomputer-based Simulations for Training Fundamental Teaching Skills. Journal of Teacher Education, 38, 20-26.

Tabachnik, B. R., and Zeichner, K. M. (1984). The Impact of Student Teaching Experience on the Development of Teacher Perspectives. Journal of Teacher Education, 35, 28-36. 
